\title{
Phobic anxiety and ischaemic heart disease
}

\author{
A P HAINES, J D IMESON, T W MEADE
}

\begin{abstract}
A prospective study of the relation between scores on the six subscales of the Crown-Crisp experiential index and subsequent incidence of ischaemic heart disease was undertaken among participants in the Northwick Park heart study. Results from 1457 white men aged 40-64 at recruitment showed that phobic anxiety was strongly related to subsequent major ischaemic heart disease (fatal and non-fatal events combined) when other associated variables were taken into account. The phobic anxiety score alone remained significantly associated with ischaemic heart disease when scores on all the subscales were included in the analysis. Phobic anxiety seemed to be particularly associated with fatal ischaemic heart disease but was not associated with deaths from other causes and was no higher in those with a pre-existing myocardial infarction at recruitment than in those without. There was a consistent increase in risk of fatal ischaemic heart disease with score on the phobic anxiety subscale. The relative risk for those whose score was 5 and above was 3.77 (95\% confidence interval 1.64 to 8.64 ) compared with those whose score was 0 or 1 . The 49 participants with evidence of myocardial infarction at recruitment had higher scores on the subscales for free floating anxiety and functional somatic complaint.

The Crown-Crisp experiential index is simple to fill out and acceptable to patients. When the results are combined with other known risk factors it may be of use in defining high risk subjects and in planning strategies for prevention.
\end{abstract}

\section{Introduction}

The possibility that psychosocial factors are important in the pathogenesis of ischaemic heart disease has been extensively

\footnotetext{
MRC Epidemiology and Medical Care Unit, Northwick Park Hospital, Harrow, Middlesex HA1 3UJ

A P HAINES, MD, MRCP, consultant epidemiologist

J D IMESON, MA, MSC, statistician

$T$ W MEADE, DM, FRCP, director
}

Correspondence and requests for reprints to: Professor A P Haines, Department of Primary Health Care, University College London School of Medicine, Highgate Wing, Whittington Hospital, London N19 5HT. investigated. ${ }^{1}$ With the possible exception of type A behaviour, characterised as competitive, aggressive, and impatient, ${ }^{23}$ psychosocial factors have not been widely accepted as being of practical relevance. The limited clinical application of psychosocial risk factors in planning the prevention of ischaemic heart disease may be partly due to difficulties of measuring psychological traits and symptoms simply and reproducibly. Further evidence for the role of psychosocial factors in major coronary events comes from the observation that adverse life events such as bereavement $t^{4}$ or disasters such as earthquakes ${ }^{5}$ are also associated with an increased risk of fatal ischaemic heart disease. Many studies have reported the psychological characteristics of patients who have developed symptoms of ischaemic heart disease, but interpretation is complicated by the possibility that any differences may be a consequence rather than an antecedent of ischaemic heart disease.

We report the relation between scores on the Crown-Crisp experiential index, ${ }^{6}$ which measures both personality traits and symptoms, and the subsequent incidence of ischaemic heart disease in the Northwick Park heart study. (A previous study that used the index picked out individual questions and attempted to determine which combination discriminated most effectively between those who did or did not later experience myocardial infarction. ${ }^{7}$ Such an approach, however, is particularly liable to turn up spurious associations purely by chance. ${ }^{8}$ )

This report highlights the association of phobic anxiety with ischaemic heart disease. People with high levels of phobic anxiety feel anxious in specific situations, but if these are avoided they do not feel anxious. The Crown-Crisp experiential index asks about common phobias such as fear of enclosed spaces, illness, going out alone, heights, and crowds.

\section{Methods}

The main purpose of the Northwick Park heart study was to investigate the thrombotic component of ischaemic heart disease by including measures of haemostatic function along with more familiar risk factors. Its design, conduct, and principal results have been described elsewhere. ${ }^{911}$ The initial response rate was about $80 \%$. In summary, about 3500 people from three occupational groups in north west London were recruited from 1972 to 1978 and followed up from 1978 to 1984 . All participants were given a CrownCrisp experiential index form and asked to return it in a prepaid envelope when they had completed it. The index is a standardised self rating inventory of 48 questions allowing scores of $0-16$ on each of six scales that measure free floating anxiety, phobic anxiety, obsessionality and obsessional neuroses, 
TABLE I-Age adjusted scores on subscales of Crown-Crisp experiential index at recruitment according to experience of clinical ischaemic heart disease during follow up

\begin{tabular}{|c|c|c|c|c|c|c|}
\hline & $\begin{array}{l}\text { Free } \\
\text { floating } \\
\text { anxiety }\end{array}$ & $\begin{array}{l}\text { Phobic } \\
\text { anxiety }\end{array}$ & $\begin{array}{l}\text { Obsessional } \\
\text { neurosis }\end{array}$ & $\begin{array}{l}\text { Functional } \\
\text { somatic } \\
\text { complaint }\end{array}$ & Depression & $\begin{array}{c}\text { "Hysteria" } \\
\text { (extraversion) }\end{array}$ \\
\hline \multicolumn{7}{|c|}{ Alive at end of follow up; no ischaemic heart disease $(n=1237)$} \\
\hline $\begin{array}{l}\text { Median } \\
\text { Lower quartile } \\
\text { Upper quartile }\end{array}$ & $\begin{array}{l}2 \cdot 7 \\
1.2 \\
5 \cdot 1\end{array}$ & $\begin{array}{l}3 \cdot 0 \\
1.0 \\
4 \cdot 0\end{array}$ & $\begin{array}{l}6.5 \\
4.4 \\
8.7\end{array}$ & $\begin{array}{l}3.4 \\
1.6 \\
5.3\end{array}$ & $\begin{array}{l}2 \cdot 2 \\
0.8 \\
4 \cdot 1\end{array}$ & $\begin{array}{l}2 \cdot 9 \\
1 \cdot 1 \\
5 \cdot 0\end{array}$ \\
\hline \multicolumn{7}{|c|}{ Non-fatal ischaemic heart disease $(n=57)^{\star}$} \\
\hline $\begin{array}{l}\text { Median } \\
\text { Lower quartile } \\
\text { Upper quartile }\end{array}$ & $\begin{array}{l}3 \cdot 0 \\
1 \cdot 2 \\
5 \cdot 7\end{array}$ & $\begin{array}{l}3.0 \\
1.5 \\
5.0\end{array}$ & $\begin{array}{l}7 \cdot 1 \\
5 \cdot 2 \\
8 \cdot 8\end{array}$ & $\begin{array}{l}4 \cdot 1 \\
2.5 \\
5.5\end{array}$ & $\begin{array}{l}2 \cdot 2 \\
0 \cdot 8 \\
5 \cdot 6\end{array}$ & $\begin{array}{l}3 \cdot 2 \\
1.0 \\
6 \cdot 4\end{array}$ \\
\hline \multicolumn{7}{|c|}{ Fatal ischaemic heart disease $(n=56)^{\star}$} \\
\hline $\begin{array}{l}\text { Median } \\
\text { Lower quartile } \\
\text { Upper quartile }\end{array}$ & $\begin{array}{l}3 \cdot 1 \\
1 \cdot 2 \\
6 \cdot 4\end{array}$ & $\begin{array}{l}4 \cdot 0 \\
3.0 \\
6.0\end{array}$ & $\begin{array}{l}7 \cdot 6 \\
5 \cdot 3 \\
9 \cdot 2\end{array}$ & $\begin{array}{l}3.9 \\
1.9 \\
5.9\end{array}$ & $\begin{array}{l}3 \cdot 3 \\
0.9 \\
5 \cdot 6\end{array}$ & $\begin{array}{l}3 \cdot 1 \\
1 \cdot 1 \\
6 \cdot 9\end{array}$ \\
\hline \multicolumn{7}{|c|}{ All ischaemic heart disease (fatal and non-fatal) $(n=105)$} \\
\hline $\begin{array}{l}\text { Median } \\
\text { Lower quartile } \\
\text { Upper quartile } \\
\text { p Valuef }\end{array}$ & $\begin{array}{l}3 \cdot 1 \\
1 \cdot 2 \\
6 \cdot 2 \\
0 \cdot 09\end{array}$ & $\begin{array}{l}4.0 \\
2.0 \\
5 \cdot 5 \\
0.0009\end{array}$ & $\begin{array}{l}7 \cdot 4 \\
5 \cdot 2 \\
9 \cdot 1 \\
0 \cdot 02\end{array}$ & $\begin{array}{l}4.0 \\
1.9 \\
5.8 \\
0.08\end{array}$ & $\begin{array}{l}3.0 \\
0.9 \\
5.6 \\
0.05\end{array}$ & $\begin{array}{l}3 \cdot 2 \\
1 \cdot 1 \\
6 \cdot 4 \\
0 \cdot 04\end{array}$ \\
\hline
\end{tabular}

Quartiles refer to cutting points.

ॠ Eight men had a non-fatal episode of ischaemic heart disease followed by a fatal episode and are therefore included in both groups but are included only once in all ischaemic heart disease. tFor comparison of all ischaemic heart disease with those alive and free of disease at end of follow up adjusted for smoking and age.

TABLE II-Distribution of phobic anxiety score

\begin{tabular}{lccccccccccccc}
\hline Score: & 0 & 1 & 2 & 3 & 4 & 5 & 6 & 7 & 8 & 9 & 10 & 11 & 12 \\
No of patients: & 195 & 204 & 260 & 227 & 204 & 153 & 79 & 64 & 26 & 21 & 15 & 5 & 4
\end{tabular}

recruitment and clinical follow up was 6.7 years (range $2 \cdot 1-12 \cdot 6)$. Of the 1511 men, $99(6.6 \%)$ died before their re-examination was due (and 44 died after re-examination). Of the remaining 1412 men, $1279(90 \cdot 6 \%)$ were clinically re-examined at or about six years after recruitment. For $46(3 \cdot 3 \%)$ only documentary information at three years was available. For another 47 (3.3\%) who were not re-examined documentary information was available six years after recruitment. For $\mathbf{4 0}$ men $(2 \cdot 8 \%)$ no evidence was available on non-fatal myocardial infarction.

When notifications of deaths were received or when there was any reason to suppose that non-fatal myocardial infarction had occurred further details were sought from general practitioners, hospitals, and coroners. Information thus obtained was then assessed by three doctors independent of the study, who decided whether deaths were attributable to ischaemic heart disease and used the World Health Organisation criteria in assessing non-fatal events of myocardial infarction. ${ }^{\text {is }}$ The term "all ischaemic heart disease" refers to the sum of fatal and non-fatal events in those without a history of myocardial infarction.

We have previously shown that scores on most of the subscales are related to age and smoking habit. ${ }^{16}$ These variables together with social class, shift (night or day), systolic blood pressure, factor VII activity, fibrinogen concentration, and cholesterol concentration were included in survival analyses using Cox's proportional hazards model, ${ }^{17}$ which takes into account the varying length of followup, to establish the independent contribution of scores on the subscales of the Crown-Crisp experiential index to the subsequent incidence of ischaemic heart disease. Deaths from causes other than ischaemic heart disease were included in the analysis as censored observations.

Logistic regression analysis was used to compare scores in those who had evidence of a previous myocardial infarction at entry to the study with scores in those who did not. ${ }^{18}$ Medians and quartile cutting points are shown in table $I$ as the scores on the subscales of the Crown-Crisp experiential index are not normally distributed. Survival analyses and logistic regression analysis do not, however, mean making assumptions about the normality of the distribution.

TABLE III-Relative risks (with $95 \%$ confidence intervals) and numbers of men developing fatal or non-fatal ischaemic heart disease according to phobic anxiety score

\begin{tabular}{|c|c|c|c|c|c|c|c|c|}
\hline \multirow{2}{*}{$\begin{array}{l}\text { Phobic anxiety } \\
\text { score }\end{array}$} & \multicolumn{2}{|r|}{$\begin{array}{l}\text { Fatal ischaemic } \\
\text { heart disease }\end{array}$} & \multicolumn{2}{|c|}{$\begin{array}{c}\text { Non-fatal ischaemic } \\
\text { heart disease }\end{array}$} & \multicolumn{2}{|r|}{$\begin{array}{l}\text { All ischaemic } \\
\text { heart disease }\end{array}$} & \multirow{2}{*}{$\begin{array}{l}\text { Alive at end of } \\
\text { follow up; } \\
\text { no ischaemic } \\
\text { heart disease }\end{array}$} & \multirow[b]{2}{*}{ Tota } \\
\hline & No & Relative risk & No & Relative risk & No & Relative risk & & \\
\hline $\begin{array}{l}0 \text { or } 1 \\
2\end{array}$ & $\begin{array}{l}7 \\
6\end{array}$ & \multirow{3}{*}{$\begin{array}{c}1.0 \\
1.31 \\
(0.45 \text { to } 3.87) \\
2.54 \\
(1.08 \text { to } 5.98) \\
3.77 \\
(1.64 \text { to } 8.64)\end{array}$} & $\begin{array}{l}14 \\
10\end{array}$ & \multirow{3}{*}{$\begin{array}{c}1 \cdot 0 \\
1 \cdot 10 \\
(0.49 \text { to } 2 \cdot 43) \\
1 \cdot 14 \\
(0.57 \text { to } 2 \cdot 28) \\
1 \cdot 26 \\
(0.62 \text { to } 2.54)\end{array}$} & $\begin{array}{l}20 \\
15\end{array}$ & \multirow{3}{*}{$\begin{array}{c}1.0 \\
1.15 \\
(0.60 \text { to } 2.20) \\
1.50 \\
(0.87 \text { to } 2.58) \\
2.09 \\
(1.24 \text { to } 3.52)\end{array}$} & $\begin{array}{l}350 \\
228\end{array}$ & $\begin{array}{l}370 \\
243\end{array}$ \\
\hline 3 or 4 & 19 & & 17 & & 32 & & 361 & 393 \\
\hline$\geqslant 5$ & 24 & & 16 & & 38 & & 298 & 336 \\
\hline Total & 56 & & 57 & & 105 & & 1237 & 1342 \\
\hline
\end{tabular}

^Eight men had an episode of non-fatal ischaemic heart disease followed by a fatal episode.

functional somatic complaint, depression, and "hysteria" (extraversion). It has been validated in psychiatric outpatients and used extensively in other studies. ${ }^{6}$ 12-14

This report is limited to white men aged 40-64 at recruitment because of the small numbers in other groups. Of the 1511 men in this category, 109 were considered by independent assessors to have experienced a first episode of major ischaemic heart disease (non-fatal infarction or coronary death) during the follow up period (10 of these having had a non-fatal myocardial infarction preceding a fatal episode). Of the $1457(96.4 \%)$ who completed the questionnaire, 105 had a first major episode of ischaemic heart disease during the follow up period, of whom eight had a non-fatal myocardial infarction preceding a fatal episode. Forty nine men with evidence of a previous myocardial infarction at entry to the study and 66 men who died of causes other than ischaemic heart disease during follow up have been excluded from tables I and III.

Follow up to establish mortality was through automatic notification of deaths through the National Health Service central register. This follow up was from April 1972 to September 1985, the mean follow up interval for mortality being 10.0 years (range 7.3-13.5). All but one of the 1511 men were successfully identified in the register. Three deaths outside the United Kingdom were recorded. Ascertainment of non-fatal myocardial infarction was based principally on clinical re-examinations planned for six years after recruitment. Questionnaires were also sent to each man and his general practitioner three years after recruitment. The mean interval between

\section{Results}

Table I shows the median scores (adjusted to age 50) for each of the six subscales in men who developed clinical ischaemic heart disease during follow up and those who did not. The median scores on the phobic anxiety subscale for all ischaemic heart disease were close to those for fatal ischaemic heart disease. This was chiefly because the scale used was discrete. Survival analysis showed that scores on each of the scales were significantly related to all ischaemic heart disease events at the $10 \%$ level, at least, after age and cigarette smoking had been taken into account, the most obvious effect being for phobia $(p=0.0009)$.

Survival analysis for fatal ischaemic heart disease showed only the obsession $(p=0.02)$ and phobia $(p=0.0007)$ subscores to be significantly related to ischaemic heart disease independently of age and cigarette smoking. Further survival analyses including scores on all the six scales showed a significant independent contribution only for phobia $(p=0.004$, fatal ischaemic heart disease; $p=0.02$, all ischaemic heart disease). The reduction in the strength of association in this analysis was due to intercorrelations between scores on the subscales. When fibrinogen concentration, cholesterol concentration, factor VII activity, and systolic blood pressure were included in the survival analyses with the score on the phobic anxiety subscale there remained a significant association of the phobia score with fatal ischaemic heart disease $(p=0.0006)$ and all ischaemic heart disease $(p=0.001)$. There was no significant difference in phobia scores 
between those who died within 24 hours of the onset of symptoms and those who died later. None of the scores on the subscales were significantly related to non-fatal myocardial infarction.

Table II shows the distribution of the phobia scores (not adjusted for age). Table III shows the relative risk (and 95\% confidence intervals) of both fatal and non-fatal ischaemic heart disease by approximate quartiles of phobia score. The risk seemed to rise quite consistently with phobia score. There was no evidence of high levels of phobic anxiety in men who died from causes other than ischaemic heart disease. Phobic anxiety score was not significantly related to stated alcohol consumption.

Phobia score seemed to maintain its predictive effect in those under and over 60 and was of similar magnitude in those in whom an episode of ischaemic heart disease occurred in the first five years of follow up and those with a later episode.

The attributable fraction of fatal ischaemic heart disease related to scores on the phobia scale above the median (3) was $49 \%$. For scores in the upper quartile ( 5 and above) it was $24 \%$. In the case of non-fatal ischaemic heart disease the attributable fraction was much lower, being $5 \%$ for phobia scores of 5 and above and $9 \%$ for scores above the median.

Table IV shows that levels of phobic anxiety were not raised in those who had evidence of a previous myocardial infarction at entry to the study, although scores on the subscales for free floating anxiety and functional somatic disorder were considerably higher.

TABLE IV-Age adjusted scores on subscales of Crown-Crisp experiential index at recruitment

\begin{tabular}{|c|c|c|c|c|c|c|}
\hline & $\begin{array}{c}\text { Free } \\
\text { floating } \\
\text { anxiety }\end{array}$ & $\begin{array}{l}\text { Phobic } \\
\text { anxiety }\end{array}$ & $\begin{array}{c}\text { Obsessional } \\
\text { neurosis }\end{array}$ & $\begin{array}{l}\text { Functional } \\
\text { somatic } \\
\text { complaint }\end{array}$ & Depression & $\begin{array}{l}\text { "Hysteria" } \\
\text { (extraversion) }\end{array}$ \\
\hline \multicolumn{7}{|c|}{ No myocardial infarction at recruitment $(n=1408)$} \\
\hline $\begin{array}{l}\text { Median } \\
\text { Lower quartile } \\
\text { Upper quartile }\end{array}$ & $\begin{array}{l}2 \cdot 4^{\star \star \star \star} \\
1 \cdot 2 \\
5 \cdot 1\end{array}$ & $\begin{array}{l}3.0 \\
1.0 \\
5.0\end{array}$ & $\begin{array}{l}6.5 \\
4 \cdot 4 \\
8 \cdot 8\end{array}$ & $\begin{array}{l}3 \cdot 4^{\star \star} \\
1 \cdot 7 \\
5 \cdot 4\end{array}$ & $\begin{array}{l}2 \cdot 2 \\
0 \cdot 8 \\
4 \cdot 1\end{array}$ & $\begin{array}{l}3 \cdot 0 \\
1 \cdot 1 \\
5 \cdot 1\end{array}$ \\
\hline \multicolumn{7}{|c|}{ Myocardial infarction at recruitment $(n=49)$} \\
\hline $\begin{array}{l}\text { Median } \\
\text { Lower quartile } \\
\text { Upper quartile }\end{array}$ & $\begin{array}{l}4 \cdot 3 \star 3 \star \star \\
2 \cdot 3 \\
7 \cdot 2\end{array}$ & $\begin{array}{l}3.0 \\
2.0 \\
5.0\end{array}$ & $\begin{array}{l}6.3 \\
4.9 \\
8.8\end{array}$ & $\begin{array}{l}5 \cdot 0^{\star \star} \\
3 \cdot 1 \\
6.6\end{array}$ & $\begin{array}{l}2 \cdot 6 \\
1 \cdot 5 \\
3 \cdot 8\end{array}$ & $\begin{array}{l}3 \cdot 2 \\
2 \cdot 1 \\
5 \cdot 3\end{array}$ \\
\hline
\end{tabular}

Quartiles refer to cutting points.

${ }_{\star \star} p=0 \cdot 002,{ }^{\star \star \star} p=0 \cdot 0006$ by logistic regression analysis.

\section{Discussion}

The score on the phobia scale of the Crown-Crisp experiential index and the subsequent incidence of ischaemic heart disease were associated; this was particularly clear in the case of fatal events and was independent of the contribution of other variables to the incidence of ischaemic heart disease. Thus, although scores on several of the subscales are significantly higher among smokers, ${ }^{16}$ this does not seem to be the explanation for the association of phobic anxiety with ischaemic heart disease. The estimates of the attributable fraction of deaths from ischaemic heart disease due to phobic anxiety suggest that this variable may be a major contributor to the risk of fatal ischaemic heart disease. These estimates, however, must be interpreted with some caution as they were derived from the data set in which the original observations were made and thus may overestimate the magnitude of the contribution. A study of an independent population would give a better estimate. Phobic anxiety was not associated with death from other causes so the relation may well be specific for ischaemic heart disease. Phobic anxiety scores were not appreciably raised in participants with evidence of clinical ischaemic heart disease at entry to the Northwick Park heart study; this suggests that the presence of ischaemic heart disease does not in itself lead to heightened phobic anxiety. Those with evidence of previous ischaemic heart disease did, however, have raised scores on the scales for free floating anxiety and functional somatic complaint, which remained when smoking habit, age, and other variables were taken into account. Although age adjusted scores on several subscales were a little higher in those who later developed ischaemic heart disease, no residual associations between characteristics other than phobia and ischaemic heart disease could be shown when scores on all the subscales were included in the survival analysis.
The pathways through which phobic anxiety are linked to increased risk of ischaemic heart disease require further investigation. The increased risk cannot be explained by an association with cholesterol concentration, measured haemostatic variables, or blood pressure. Hyperventilation induced by anxiety has been shown to cause coronary spasm with subsequent cardiac ischaemia. ${ }^{19}$ A recent study showed that concentrations of adrenaline were associated with infarct size. Plasma glucose concentrations were associated with mortality in non-diabetic patients with infarcts. Multiple regression analysis suggested that concentrations of cortisol, adrenaline, and noradrenaline were the major determinants of plasma glucose concentration after myocardial infarction. ${ }^{20}$ Patients with high levels of phobic anxiety might have exaggerated hormonal responses to myocardial infarction. An alternative mechanism may be by inducing fatal arrhythmias. The genesis of malignant ventricular arrhythmias may require three factors: an underlying electrical irritability of the myocardium, an intense underlying state of psychological disturbance, and a triggering event. ${ }^{21} 22$ Subjects with a tendency to phobic anxiety may have a greater vulnerability to triggering events. Arrhythmias provoked by psychological factors may not be mediated solely by the sympathetic nervous system: other pathways or neurotransmitters may be responsible. ${ }^{23}$ Investigation of patients with phobic anxiety may contribute to the understanding of these mechanisms.

The Crown-Crisp experiential index is simple to fill out and acceptable to patients; in combination with known risk factors it may be of considerable value in defining groups at high risk of ischaemic heart disease and in planning strategies for prevention.

We thank staff at $\mathrm{H} \mathrm{J} \mathrm{Heinz} \mathrm{Co} \mathrm{Ltd,} \mathrm{British} \mathrm{Telecom,} \mathrm{and} \mathrm{the} \mathrm{offices} \mathrm{of}$ the London boroughs of Harrow and Brent for their help and participation; Sir Graham Bull, Dr W E Miall, Professor R L Himsworth, Dr C J Edmonds, and Dr Gillian Greenberg for assessing cases; and laboratory, nursing, and clerical staff in the Medical Research Council Epidemiology and Medical Care Unit for their help.

\section{References}

1 Jenkins $C D$. Recent evidence supporting psychologic and social risk factors for coronary disease. N Engl f Med 1976;294:987-94, 1033-8.

2 Jenkins CD, Rosenman RH, Zyzanski SJ. Prediction of clinical coronary disease by a test for the coronary-prone behavior pattern. N Engl J Med 1974;290:1271-5.

3 Matthews KA, Haynes SG. Type A behavior pattern and coronary disease risk: update and clinical evaluation. Am $\mathcal{F}$ Epidemiol 1986;123:923-60.

4 Parkes CM, Benjamin B, Fitzgerald RG. Broken heart: a statistical study of increased mortality among widowers. BrMed $\mathcal{F} 1969 ;$ i:740-3.

5 Katsouyanni K, Kogevinas M, Trichopoulos D. Earthquake related stress and cardiac mortality. Int J Epidemiol 1986;15:326-30.

6 Crown S, Crisp AH. A short clinical diagnostic self-rating scale for psychoneurotic patients. The Middlesex Hospital questionnaire. Br ₹ Psychiatry 1966;112:917-23.

7 Crisp AH, Queenan M, D'Souza MF. Myocardial infarction and the emotional climate. Lancet 1984;i:616-9.

8 Thompson SG. Predicting myocardial infarction. Lancet 1984;i:1021-2.

9 Meade TW, North WR, Chakrabarti R, Haines AP, Stirling X. Population-based distribution of haemostatic variables. BrMed Bull 1977;33:283-8.

10 Meade TW, Chakrabarti R, Haines AP, et al. Haemostatic function and cardiovascular death: early results of a prospective study. Lancet $1980 ; \mathrm{i}: 1050-4$.

11 Meade TW, Brozovic M, Chakrabarti R, et al. Haemostatic function and ischaemic heart disease: principal results of the Northwick Park heart study. Lancet 1986;ii:533-7.

12 Crown S, Crisp AH. Manual of the Crown-Crisp experiential index. London: Hodder and Stoughton, 1979.

13 Crisp AH, Priest RG. Psychoneurotic status during the year following bereavement. F Psychosom Res 1972;16:351-5.

14 Crisp AH, McGuiness B. Jolly fat: the relation between obesity and psychoneurosis in the general population. BrMed $\mathcal{J} 1976 ;$;i:7-9.

15 World Health Organisation Regional Office for Europe. Myocardial infarction community registers. Copenhagen: WHO, 1976. (Public Health in Europe No 5.)

16 Haines AP, Imeson JD, Meade TW. Psychoneurotic profiles of smokers and non-smokers. BrMed f 1980;280:1422.

17 Hopkins A. P2L: regression with incomplete survival data. In: Dixon WJ, Brown MB, eds. BMDP statistical software. Los Angeles: University of California Press, 1983:576-94.

18 Engelman L. PLR: stepwise logistic regression. In: Dixon WJ, Brown MB, eds. BMDP statistical software. Los Angeles: University of California Press, 1983:330-44.

19 Rasmussen K, Ravnsbaek J, Funch-Jensen P, Bagger JP. Oesophageal spasm in patients with coronary artery spasm. Lancet 1986;i:174-6.

20 Oswald GA, Smith CCT, Betteridge DJ, Yudkin JS. Determinants and importance of stress hyperglycaemia in non-diabetic patients with myocardial infarction. BrMed f 1986;293:917-22.

21 Lown B. Mental stress, arrhythmias and sudden death. Am $\mathcal{f}$ Med 1982;72:177-80.

22 Lown B, De Silva RA. Roles of psychologic stress and autonomic nervous system changes in provocation of ventricular premature complexes. Am $\mathcal{f}$ Cardiol 1978;41:479-85.

provocation of ventricular premature complexes. Am f Cardiol 1978;41:479-85.
23 Verrier RL, Lown B. Behavioral stress and cardiac arrhythmias. Annu Rev Physiol 1984;46: 155-76.

(Accepted 29 April 1987) 